\title{
Modeling of Experimental Adsorption Isotherm Data for Chlorothalonil by Nairobi River Sediment
}

\section{Kamau $\mathbf{J}^{*}$ and Kamau G}

University of Nairobi, Nairobi, Kenya

\begin{abstract}
The present study deals with modeling of experimental adsorption data of chlorothalonil by Nairobi River sediment. Effects of initial concentration, different shaking time and contact time were investigated. The concentration of chlorothalonil in the clear aqueous solution $\left(\mathrm{C}_{\mathrm{e}}\right)$ was determined by reversed phase HPLC. Determinations were made using the $15 \mathrm{~cm} \mathrm{MCH}-5-\mathrm{N}-\mathrm{CAP} \mathrm{C}_{18}$ column and $85 \%$ HPLC grade acetonitrile in distilled water as the mobile phase. Adsorption isotherm study indicated that the Quasi Langmuir (Scatchard plot) fitted the experimental data with heist regression values range of 99.8 to 100 . Thermodynamic study calculations shows that the Gibbs free energy for chlorothalonil was $-9.2687 \mathrm{kj} / \mathrm{mol}$ calculated using Freundlich and Langmuir constants. The maximum adsorption capacity of Nairobi river sediment was $33.389 \mathrm{mg} / \mathrm{ml}$. Finally, Kinetics study revealed that the adsorption of chlorothalonil onto Nairobi river sediment falled a pseudo second order kinetics.
\end{abstract}

Keywords: Adsorption; Chlorothalonil; Isotherms; Kinetics; Thermodynamics

\section{Introduction}

Use of pesticide residues is accompanied by environmental pollution. When a pesticide molecule is applied, it undergo leaching, vaporization, adsorption, degradation, hydrolysis among other processes. Adsorption/desorption phenomenon is one of the most effective technologies used to remove persistent pesticide molecules in the environment. To effectively use adsorption/desorption process in environmental protection, scientist apply adsorption isotherm models. Adsorption isotherm is generally a curve describing the phenomenon governing the mobility and the retention of a substance from the aqueous porous media or aquatic environments to a solidphase at a constant temperature and $\mathrm{pH}[1,2]$. The ratio between the adsorbed amount with the remaining in the solution (adsorption equilibrium) is established when an adsorbate containing phase and adsorbate concentration in the bulk solution has been contacted with the adsorbent for sufficient time [3,4]. Typically, the mathematical correlation, which constitutes an important role towards the modeling analysis, operational design and applicable practice of the adsorption systems, is usually depicted by graphically expressing the solid-phase against its residual concentration [5]. Its physicochemical parameters together with the underlying thermodynamic assumptions which provide an insight into the adsorption mechanism, surface properties as well as the degree of affinity of the adsorbents [6]. Scientist have constantly formulated equilibrium isotherm models which include Langmuir, Freundlich, Brunauer-Emmett-Teller, RedlichPeterson, Dubinin-Radushkevich, Temkin, Toth, Koble-Corrigan, Sips, Khan, Hill, Flory-Huggins and Radke-Prausnitz isotherms in terms of three fundamental approaches [7] Kinetic consideration is the first approach to be referred. Hereby, adsorption equilibrium is defined being a state of dynamic equilibrium, with both adsorption and desorption rates are equal [8]. Thermodynamics is the second approach which provide a framework of deriving numerous forms of adsorption isotherm models [9,10]. Thirdly potential theory is the third approach which conveys the main idea in the generation of characteristic curve [10]. The trend of the isotherm modeling is the derivation in more than one approach, thus directing to the difference in the physical interpretation of the model parameters $[11,12]$. This paper focusses on modelling of adsorption isotherms of chlorothalonil onto Nairobi River sediment as a subject of initial concentration and shaking time.

\section{Experimental Materials and Reagents}

Chlorothalonil (IOBA Chemmie, 99\% pure) acetone (Panreac quimica, 95\%) and Acetonitrile (HPLC analytical grade 85\% from Fisher Scientific Co. (Fairlawn, NJ). were used as received. An orbital shaker fitted stopwatch was used for all timing purposes. Distilled water was used for all preparations. The sediments used in these experiments were collected from the Nairobi River which is about $200 \mathrm{~m}$ from the Department of Chemistry, University of Nairobi.

\section{Instrumentation}

All UV-Visible spectrophotometric measurements were taken on UV-Visible spectrophotometer (1700 model, Shimadzu Corporation, Kyoto Japan). All reversed phase chromatographic measurements were done using a HPLC instrument (Shimadzu Corporation, Kyoto Japan) fitted with a tunable SPD-20A Prominence UV-Vis detector and a Prominence LC and CTO-10-AS VP Shimadzu column oven. A $15 \mathrm{~cm}$ MCH-5-N-CAP C ${ }_{18}$ column was employed. A Fischer scientific A-160, analytical balance was used for all weight measurements.

\section{Procedure}

Solutions of chlorothalonil in acetone in the concentration range 0-100 ppm were prepared. Each of the 20, 40, 60, 80, 100 ppm solutions prepared was scanned using the UV-Vis spectrophotometer on a wavelength range of between $200-900 \mathrm{~nm}$.

\section{Sorption experiment}

In order to model the experimental data, $0.5 \mathrm{~g}$ of the dried sediment was shaken with $10 \mathrm{ml}$ distilled water spiked at 100, 200, 300, 400 and $500 \mathrm{mg} / \mathrm{ml}$ levels of chlorothalonil. Each of the samples in quadruplicate was shaken for 15, 30, 45 and 60 minutes in an Orbital shaker. The

*Corresponding author: Kamau J, University of Nairobi, Nairobi, Kenya, Tel: +254724305124; E-mail: djames085@gmail.com

Received November 25, 2016; Accepted December 22, 2016; Published January 03, 2017

Citation: Kamau J, Kamau G (2017) Modeling of Experimental Adsorption Isotherm Data for Chlorothalonil by Nairobi River Sediment. Mod Chem Appl 5 203. doi: $10.4172 / 2329-6798.1000203$

Copyright: $\odot 2017 \mathrm{Kamau}$ J, et al. This is an open-access article distributed under the terms of the Creative Commons Attribution License, which permits unrestricted use, distribution, and reproduction in any medium, provided the original author and source are credited. 
sediment was then allowed to settle for $12 \mathrm{hrs,} \mathrm{after} \mathrm{which} \mathrm{the} \mathrm{water}$ phase was decanted, and then filtered through Whatman A40 filter paper. The concentration of chlorothalonil in the clear aqueous solution $\left(\mathrm{C}_{\mathrm{e}}\right)$ was determined by reversed phase HPLC. Determinations were made using the $15 \mathrm{~cm} \mathrm{MCH}-5$ - N-CAP $\mathrm{C}_{18}$ column and $85 \%$ HPLC grade acetonitrile in distilled water as the mobile phase. An assumption made in arriving at the modelling data was that the addition of sediment to the solution does not alter the volume of the solution significantly. The data was fitted into Freundlich, Langmuir, Quasi Langmuir 1, Temkin, Dubinin-Radushkevich and Scatchard isotherm models [13]. Adsorption kinetics constants was determined using Pseudo first order, Pseudo second order and intraparticle diffusion model [14-17]. The amount adsorbed $(\mathrm{mg} / \mathrm{g})$ was calculated using the formulae reported by Vanderborght and van Greikenm [18].

$$
Q_{\mathrm{e}}=\mathrm{V}\left(C_{\mathrm{i}}-C_{\mathrm{e}}\right)
$$

Where $Q_{e}$ is the amount of solute adsorbed from the solution, $\mathrm{V}$ is the volume of the adsorbate, $C_{i}$ is the concentration before adsorption, $C_{e}$ is the concentration after adsorption, and $w$ is the weight in gram of the adsorbent.

\section{Results and Discussion}

The sorption isotherms of chlorothalonil by Nairobi River sediment were studied by fitting the obtained data to Freundlich, Langmuir, Quasi Langmuir 1, Quasi Langmuir 2, Temkin, Dubinin-Radushkevich and Scatchard isotherm models.

\section{Langmuir isotherms}

The Langmuir [19] model assumes that uptake of pesticide molecule occurs on a homogenous surface by monolayer adsorption without any interaction between adsorbed molecules and uniform energies of adsorption. The Langmuir equation

$$
\mathrm{q}_{\mathrm{e}}=\mathrm{q}_{\mathrm{m}} \mathrm{bC}_{\mathrm{e}} / 1+\mathrm{bC}_{\mathrm{e}}
$$

where $q e$ is the amount adsorbed $(\mathrm{mg} / \mathrm{g}), C_{e}$ is the equilibrium concentration of the pesticide molecule $(\mathrm{mg} / \mathrm{L}), q m(\mathrm{mg} / \mathrm{g})$ is the maximum amount of adsorbed molecules per unit mass of sorbent corresponding to complete coverage of the adsorptive sites, $K_{L}(\mathrm{~L} / \mathrm{mg})$ is the Langmuir constant related to the energy of adsorption. This can further be written as:

$$
\mathrm{C}_{\mathrm{e}} / \mathrm{q}_{\mathrm{e}}=1 / \mathrm{b} \mathrm{Q}^{0}+\mathrm{C}_{\mathrm{e}} / \mathrm{Q}^{0}
$$

A plot of $C_{e} / q_{e}$ versus $C_{e}$ gives a straight line with intercept of $1 / b$ $\mathrm{Q}^{0}$ and slope of $1 / \mathrm{Q}^{0}$ (Figure 1 )

The regression values obtained for the Langmuir adsorption isotherm model ranged from 65.8 to 93.3 . The Langmuir constant $b$ increases with shaking time. The Langmuir constant b is 44.8504 (Table 1 ).

\section{Quasi Langmuir isotherm 1}

A special case of Langmuir is described in the following equation [20]

$$
\mathrm{q}_{\mathrm{e}}=\mathrm{Q}_{\mathrm{o}} \mathrm{K}_{\mathrm{L}} \mathrm{C}_{\mathrm{e}} / 1+\mathrm{K}_{\mathrm{L}} \mathrm{C}_{\mathrm{e}}
$$

Equation 4 can be linearized as follows

$$
1 / \mathrm{q}_{\mathrm{e}}=\left(1 / \mathrm{K}_{\mathrm{L}} \mathrm{Q}_{0}\right) 1 / \mathrm{C}_{\mathrm{e}}+1 / \mathrm{Q}_{0}
$$

This means a plot of $1 / \mathrm{q}_{\mathrm{e}}$ versus $1 / \mathrm{C}_{\mathrm{e}}$ is linear with $1 / \mathrm{K}_{\mathrm{L}} \mathrm{Q}_{0}$ as the slope and intercept as $1 / \mathrm{Q}_{0}$ and is shown by Figure 2. Being a modified Langmuir isotherm, the data for quasi Langmuir model fitted well into $t(R \geq 0.87 .4)$ (Table 2). The Langmuir constant values, $K_{L}$ ranges from 0.00219 to 0.02051 . The isotherm can be explained by a dimensionless constant separation parameter given below

$$
\mathrm{R}=1 /\left[1+\mathrm{K}_{\mathrm{L}} \mathrm{C}_{\mathrm{o}}\right]
$$

If the value of $\mathrm{R}_{\mathrm{L}}$ lies between 0 and 1 , the adsorption process is favorable, if $\mathrm{R}_{\mathrm{L}}$ is greater than 1 , the adsorption process is unfavorable [21]. The RL values obtained in this study is greater than 1 indicating low affinity of chlorothalonil to Nairobi River sediment.

\section{Quasi Langmuir 2}

Langmuir adsorption isotherm has been modified by many scientist. In the following modification, the Langmuir adsorption has been modified linearly as shown in equation 6 below

$$
\mathrm{q}_{\mathrm{e}}=\mathrm{q}_{\mathrm{m}}-\mathrm{q}_{\mathrm{e}} / \mathrm{K}_{\mathrm{L}} \mathrm{C}_{\mathrm{e}}
$$
below.

A plot of $\mathrm{q}_{\mathrm{e}}$ versus $\mathrm{Q}_{\mathrm{e}} / \mathrm{C}_{\mathrm{e}}$ is linear and is indicated in the Figure 3

\section{Freundlich equation}

The Freundlich [22] equation is an empirical equation based on

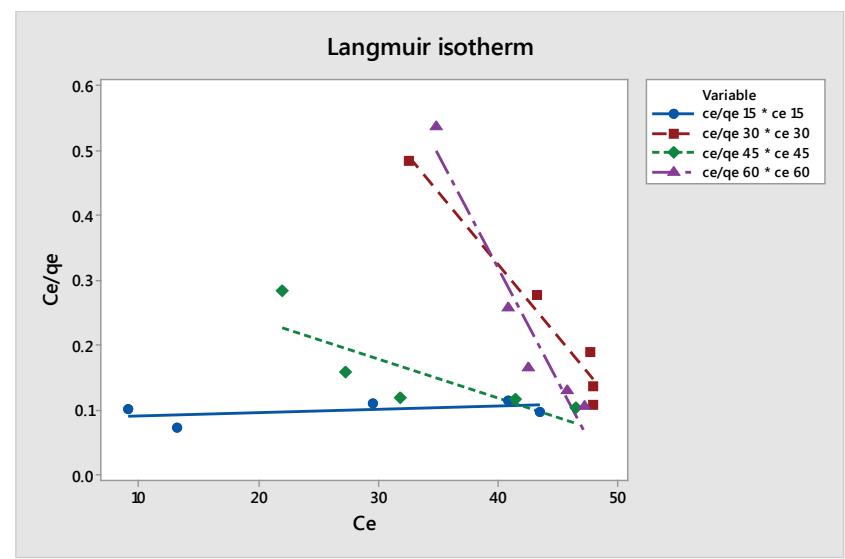

Figure 1: Lanngmuir isotherm model Assumption made is that the adsorbed chemical species do not react with one another. From Figure 1 above, the following constants are calculated.

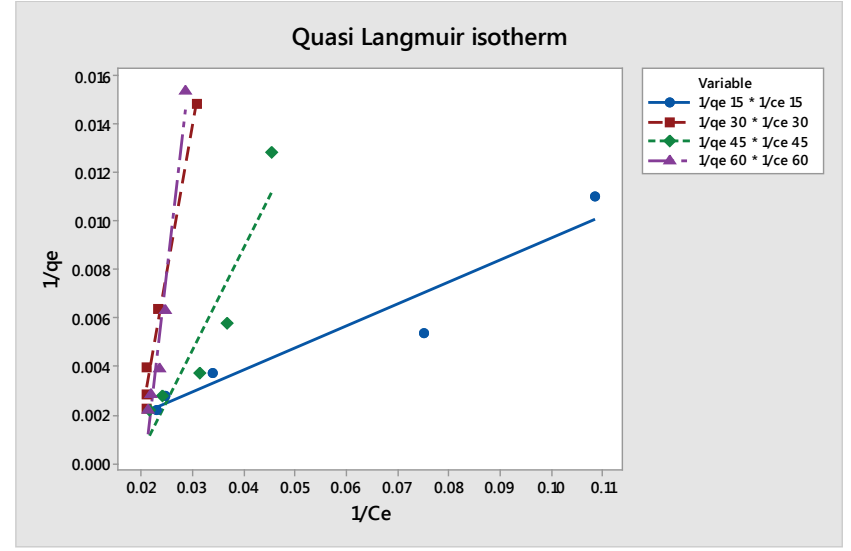

Figure 2: Quasi Langmuir adsorption isotherm model The parameters of Quasi Langmuir adsorption isotherm are stipulated in Table 2.

\begin{tabular}{|c|c|c|c|c|c|}
\hline Time in minute & $\mathbf{1 / \mathbf { Q } ^ { 0 }}$ & $\mathbf{1 / \mathbf { b } ^ { \mathbf { 0 } }}$ & $\mathbf{b}$ & $\mathbf{R}_{\mathbf{2}}$ & $\mathbf{\Delta G}$ \\
\hline 15 & 0.000528 & 0.08384 & 15.8787 & 94.3 & -12.4032 \\
\hline 30 & 0.02229 & 1.218 & 54.6433 & 95.8 & -9.7923 \\
\hline 45 & 0.005989 & 0.3583 & 59.8264 & 65.8 & -10.0141 \\
\hline 60 & 0.03540 & 1.737 & 49.0678 & 93.3 & -9.5289 \\
\hline \multicolumn{5}{|c|}{ Table 1: Langmuir adsorption isotherm parameters. } \\
\hline
\end{tabular}


adsorption on a heterogeneous surface. The equation is commonly represented as:

$$
\mathrm{q}_{\mathrm{e}}=\mathrm{K}_{\mathrm{F}} \mathrm{Ce}^{1 / \mathrm{n}}
$$

Where $\mathrm{C}_{\mathrm{e}}(\mathrm{mg} / \mathrm{L})$ is the equilibrium concentration and $\mathrm{q}_{\mathrm{e}}(\mathrm{mg} / \mathrm{g})$ is the amount adsorbed pesticide molecule per unit mass of the adsorbent. The constant $\mathrm{n}$ (measure of adsorption non-linearity between solution solute concentration and adsorption) is the Freundlich equation exponent that represents the parameter characterizing quasi-Gaussian energetic heterogeneity of the adsorption surface [23] $\mathrm{K}_{\mathrm{F}}(\mathrm{L} / \mathrm{g})$ is the Freundlich constant indicative of the relative adsorption capacity of the adsorbent (Table 3).

Taking the logarithm on both sides

$$
\ln \mathrm{q}_{\mathrm{e}}=\ln \mathrm{K}_{\mathrm{F}}+1 / \mathrm{n} \ln \mathrm{C}_{\mathrm{e}}
$$

This means that a plot of $\ln \mathrm{q}_{\mathrm{e}}$ against $\ln \mathrm{C}_{\mathrm{e}}$ is linear with slope of $1 / \mathrm{n}$ and is shown in Figure 4.

The Freundlich isotherm model is seen to fit strongly in the adsorption of chlorothalonil unto Nairobi River sediment at all contact times investigated $\left(\mathrm{R}^{2} \geq 0.89\right)$ (Table 4$)$

From the above parameters, the values of $\mathrm{K}_{\mathrm{OC}}$ was calculated from $\mathrm{K}_{\mathrm{d}}$ values. The percentage organic carbon for Nairobi River sediment was $0.85 \%$.

$$
\mathrm{K}_{\mathrm{O}}=\mathrm{K}_{\mathrm{d}} / \% \mathrm{OC}
$$

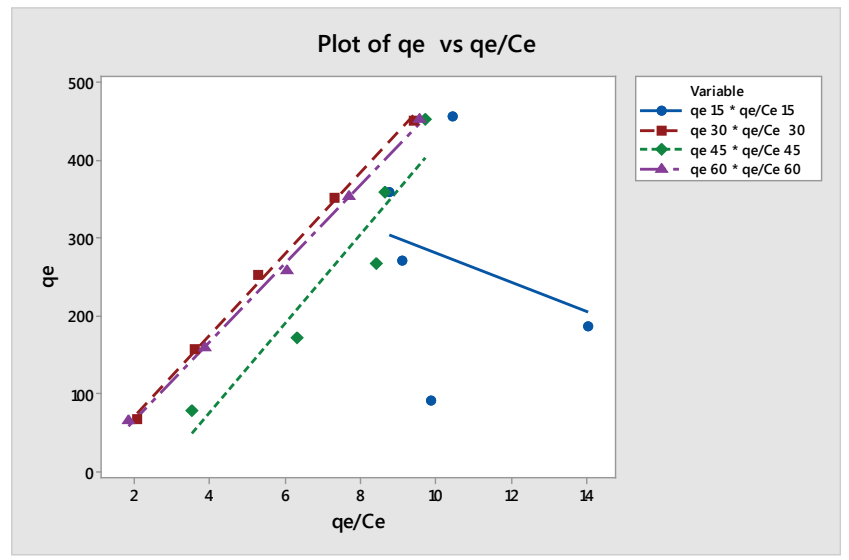

Figure 3: Quasi Langmuir isotherm model 2 Form Figure 3 above, it is evident that the slight modification of the Langmuir model does not bring any difference to the values of the Langmuir constants. The regression values obtained in this special Langmuir model ranges from 0.78 to 0.98 . This is shown in Table 3.

\begin{tabular}{|c|c|c|c|c|c|}
\hline Time in minute & $\mathbf{1 / \mathbf { K } _ { \mathbf { L } } \mathbf { Q } _ { \mathbf { 0 } }}$ & $1 / \mathbf{Q}_{\mathbf{0}}$ & $\mathbf{K}_{\mathbf{L}}$ & $\mathbf{R}_{\mathbf{L}}$ & $\mathbf{R}_{\mathbf{2}}$ \\
\hline 15 & 0.09070 & 0.000199 & 0.00219 & 0.219 & 92.1 \\
\hline 30 & 1.204 & 0.02196 & 0.01822 & 3.644 & 98.4 \\
\hline 45 & 0.420 & 0.007885 & 0.01877 & 5.631 & 87.1 \\
\hline 60 & 1.803 & 0.03698 & 0.02051 & 8.204 & 95.9 \\
\hline
\end{tabular}

Table 2: Quasi-Langmuir isotherm parameters.

\begin{tabular}{|c|c|c|c|}
\hline Time in minute & $\mathbf{q}_{\mathbf{m}}$ & $\mathbf{K}_{\mathbf{L}}$ & $\mathbf{R}_{\mathbf{2}}$ \\
\hline 15 & 472.5 & 19.10 & 7.9 \\
\hline 30 & 33.41 & 52.23 & 99.8 \\
\hline 45 & 153.6 & 57.24 & 90.3 \\
\hline 60 & 34.57 & 50.21 & 99.8 \\
\hline
\end{tabular}

Table 3: Quasi Langmuir 2 parameters.
$\mathrm{K}_{\mathrm{d}}=\mathrm{q} / \mathrm{c}$

From the above equations, $\mathrm{K}_{\mathrm{d}}=10.4631$

$\mathrm{K}_{\mathrm{OC}}=10.4631 / 0.85=12.3095$

\section{Temkin isotherm equation}

The Temkin isotherm equation assumes that the heat of adsorption of all the molecules in layer decreases linearly with coverage due to adsorbent-adsorbate interactions, and that the adsorption is characterized by a uniform distribution of the bonding energies, up to some maximum binding energy [24]. The Temkin isotherm is represented by the following equation:

$$
q_{e}=\frac{R T}{b} \operatorname{Ln}\left(K_{T} C_{e}\right)
$$

Where, $\mathrm{T}$ is the absolute temperature $(\mathrm{K}), \mathrm{R}$ is the universal gas constant $(8.314 \mathrm{~J} / \mathrm{mol} . \mathrm{K}), \mathrm{K}_{\mathrm{T}}$ is the equilibrium binding constant $(\mathrm{L} / \mathrm{mg})$, and $\mathrm{b}_{\mathrm{T}}$ is the variation of adsorption energy $(\mathrm{kJ} / \mathrm{mol}) . \mathrm{B}_{\mathrm{T}}$ is Temkin constant related to the heat of adsorption $(\mathrm{kJ} / \mathrm{mol})$. This can be rearranged linearly as:

$$
q_{e}=B_{T} \ln \left(K_{T} C_{e}\right)+B_{T} \operatorname{Ln} C_{e}
$$

Therefore a plot of $\mathrm{q}_{e}$ against $\ln \mathrm{C}_{\mathrm{e}}$ is linear (Figure 5). From the plots, the data in Tables 5 and 6 was obtained

Like in Freundlich isotherm, the curve fits better at higher contact times. This is expected since at higher contact times, equilibration is achieved and thus the adsorbents interaction has equilibrated, i.e., the rate of forward and backward reactions are equal. At lower contact times, this has not been achieved and therefore the points are more diverse (Figure 6). Dubinin-Radushkevich (D-R) Isotherm was applied to the obtained data to deduce the heterogeneity of the apparent adsorption energy on the adsorption site [24]. The equation linear form is given as

$$
\ln \mathrm{q}_{\mathrm{e}}=\ln \mathrm{q}_{\mathrm{D}}-\mathrm{B}_{\mathrm{D}} \dot{\varepsilon}^{2}
$$

\begin{tabular}{|c|c|c|c|c|c|}
\hline Time in minute & $\mathbf{1 / n}$ & $\mathbf{I n} \mathbf{K}_{\mathbf{F}}$ & $\mathbf{K}_{\mathbf{F}}$ & $\mathbf{R}_{\mathbf{2}}$ & $\mathbf{\Delta} \mathbf{G}$ \\
\hline 15 & 0.8753 & 2.724 & 15.2412 & 93.2 & -6.6672 \\
\hline 30 & 4.237 & 3.7690 & 43.337 & 89.5 & -9.2249 \\
\hline 45 & 2.219 & 2.314 & 10.1148 & 93.9 & -5.6637 \\
\hline 60 & 6.438 & 3.142 & 23.1501 & 98.7 & -7.0294 \\
\hline
\end{tabular}

Table 4: Freundlich isotherm parameters.

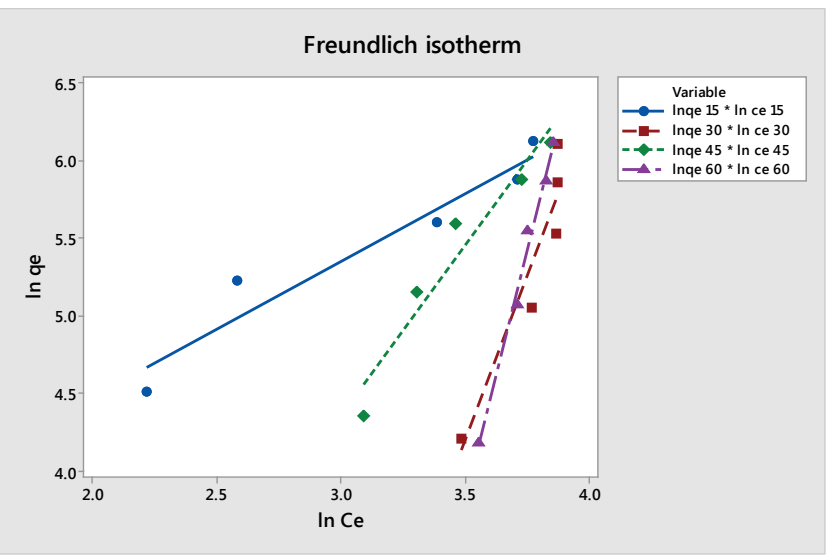

Figure 4: Adsorption isotherm from Figure 4 above, the following apparent thermodynamic parameters were calculated Table 4. 


\section{$\dot{\varepsilon}=\mathrm{R} \operatorname{Tln}\left[1+1 / \mathrm{C}_{\mathrm{e}}\right]$}

Where $\mathrm{q}_{\mathrm{D}}$ is adsorption capacity of the adsorbent, $B_{D}$ is the $D-R$ isotherm constant related to energy, $\varepsilon$ is the Polanyi potential. The plot of $\ln$ qe against $\dot{\boldsymbol{\varepsilon}}^{2}$ is shown in Figure 7. The $\mathrm{D}-\mathrm{R}$ isotherms parameters are given in Table 6 below. The mean adsorption energy $\mathrm{E}(\mathrm{kj} / \mathrm{mol}) \mathrm{can}$ be obtained from the value of $B_{D}$ by using the formula. $q_{D}$ and $B_{D}$ were obtained by a plot of ln qe against $\dot{\boldsymbol{\varepsilon}}^{2}$ as shown above (Figure 8). The energy of chlorothalonil adsorption to Nairobi River sediment was calculated according to equation 15. The parameters are recorded in Tables 7 and 8.

$$
\mathrm{E}=1 /\left[\begin{array}{ll}
2 & \mathrm{~B}_{\mathrm{D}}
\end{array}\right]^{1 / 2}
$$

When the adsorption energy is less than $8 \mathrm{kj} / \mathrm{mol}$ the sorption process is said to be dominated by physisorption (physical attachment of pesticide molecule to the soil surface), if $\mathrm{E}$ is between 8 and $16 \mathrm{kj} /$ $\mathrm{mol}$, the process is dominated by chemical ion exchange mechanism and if the value of $\mathrm{E}$ is greater than $16 \mathrm{kj} . \mathrm{mol}$ the process is dominated by chemical particle diffusion [24]. The value of $E$ obtained in this work is $4.4445 \mathrm{kj} / \mathrm{mol}$ which indicates that the adsorption of chorothanil is dominated by physisorption as earlier noted by James et al. [25]. The scatchard plot analysis is applied to obtain comprehensive information on the affinity of of binding sites and to analyze the result of the adsorption isotherms [26]. The equation is given below

$$
\mathrm{Q}_{\mathrm{e}} / \mathrm{C}_{\mathrm{e}}=\mathrm{Qb}-\mathrm{q}_{\mathrm{e}} \mathrm{b}
$$

Where $\mathrm{Q}$ and $\mathrm{b}$ are the Scatchard adsorption isotherm constants, if the plot of $\mathrm{q}_{\mathrm{e}} / \mathrm{C}_{\mathrm{e}}$ versus qe gives a straight line, the adsorbent consist

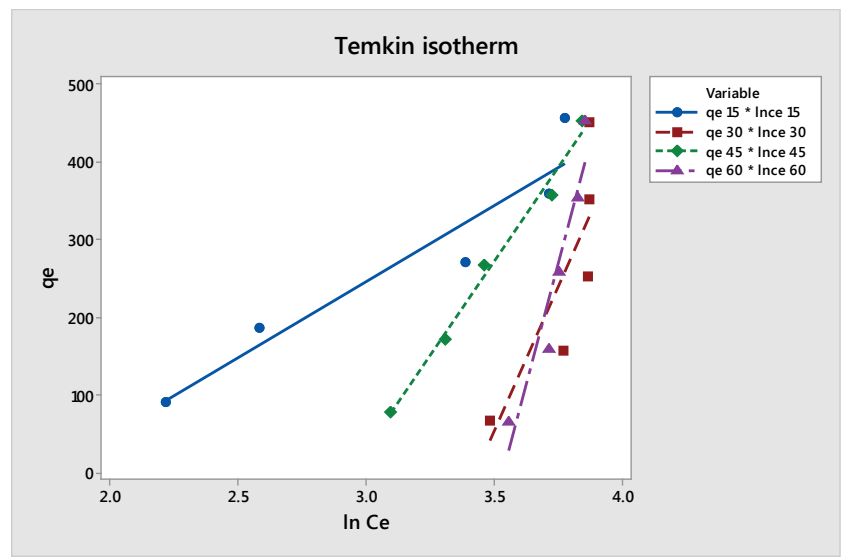

Figure 5: Temkin adsorption isotherm. The obtained values from the plots of the adsorption data obtained subject to Temkin equation are recorded in Table 5.

\begin{tabular}{|c|c|c|c|c|}
\hline Time in minute & $\mathbf{B}_{\mathbf{T}}$ & $\mathbf{B}_{\mathbf{T}} \mathbf{I n} \mathbf{K}_{\mathbf{T}}$ & $\mathbf{K}_{\mathbf{T}}$ & $\mathbf{R}_{\mathbf{2}}$ \\
\hline 15 & 195.7 & -341.1 & 0.17499 & 91.1 \\
\hline 30 & 746.0 & -2558 & 0.03862 & 66.7 \\
\hline 45 & 485.1 & -1425 & 0.05299 & 98.8 \\
\hline 60 & 1235.0 & -4361 & 0.02927 & 90.8 \\
\hline
\end{tabular}

Table 5: Temkin isotherm parameters.

\begin{tabular}{|c|c|c|c|c|c|}
\hline Time & Ln $\mathbf{q}_{\mathbf{D}}$ & $\mathbf{B}_{\mathbf{D}}$ & $\mathbf{q}_{\mathbf{D}}$ & $\mathbf{R}^{\mathbf{2}}$ & $\mathbf{E}(\mathbf{k j} / \mathbf{m o l})$ \\
\hline 15 & 5.974 & 0.000023 & 393.0748 & 93.9 & 3.7438 \\
\hline 30 & 7.137 & 0.000535 & 1257.6498 & 85.1 & 3.5709 \\
\hline 45 & 6.607 & 0.000185 & 740.2589 & 99.3 & 5.9875 \\
\hline 60 & 8.382 & 0.000874 & 4367.7357 & 97.8 & 2.9187 \\
\hline
\end{tabular}

Table 6: $D-R$ isotherm parameters.

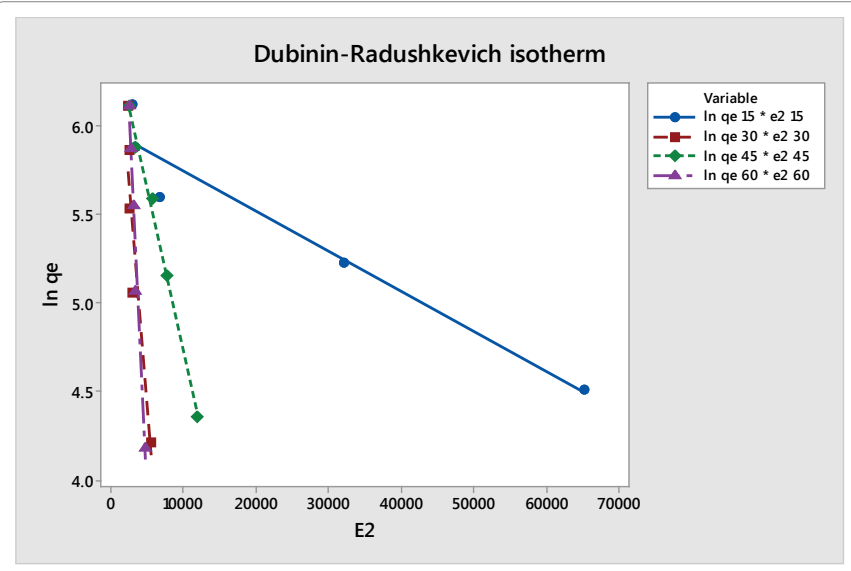

Figure 6: D-R adsorption isotherm model.

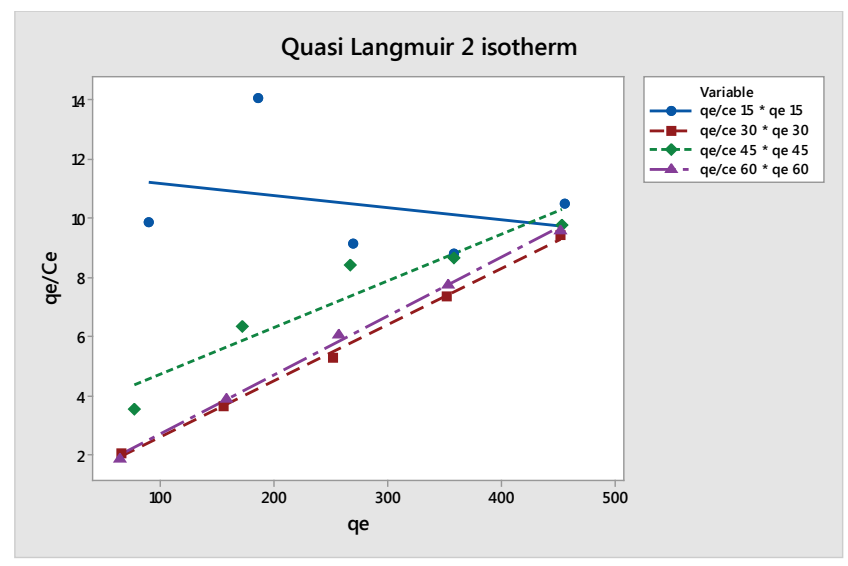

Figure 7: Scatchard adsorption isotherm model. The isotherm parameters obtained from the plots in Figure 7 are shown in Table 7 below whereby the regression ranges from 0.903 to 0.998 .

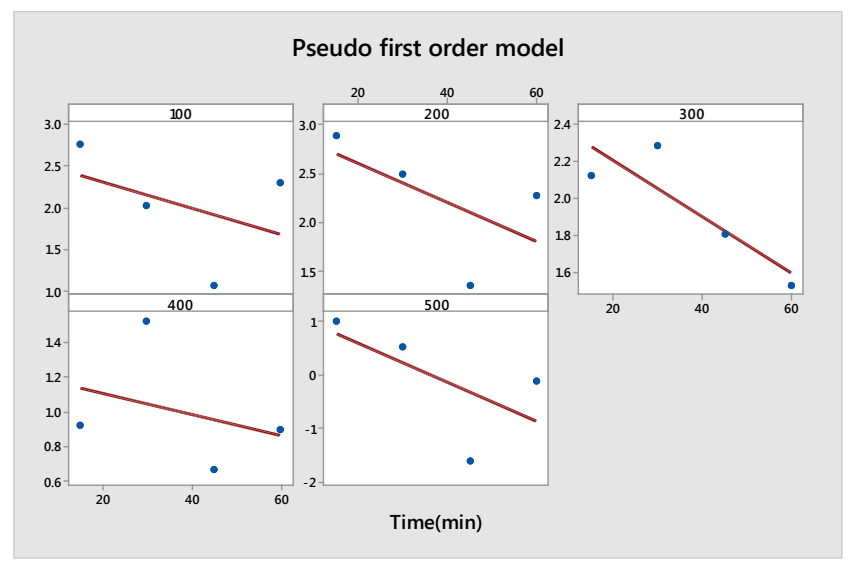

Figure 8: Pseudo first order model plot.

\begin{tabular}{|c|c|c|c|c|}
\hline Time in minute & $\mathbf{b Q}_{\mathbf{0}}$ & $\mathbf{b}$ & $\mathbf{Q}_{\mathbf{0}}$ & $\mathbf{R}_{\mathbf{2}}$ \\
\hline 15 & 2.6010 & 0.01416 & 183.6864 & 97.9 \\
\hline 30 & 0.6499 & 0.01578 & 41.18501 & 90.3 \\
\hline 45 & 3.133 & 0.01910 & 164.0314 & 99.8 \\
\hline 60 & 0.7004 & 0.01987 & 35.24911 & 99.8 \\
\hline
\end{tabular}

Table 7: Scatchard plot analysis parameter. 


\begin{tabular}{|c|c|c|c|}
\hline Initial Conc & $\mathbf{I n q}_{\mathbf{e}}$ & $\mathbf{k}_{\mathbf{f}}$ & $\mathbf{R}^{\mathbf{2}}$ \\
\hline 100 & 2.625 & 0.01559 & 18.0 \\
\hline 200 & 2.996 & 0.01975 & 35.0 \\
\hline 300 & 2.502 & 0.01511 & 75.1 \\
\hline 400 & 1.231 & 0.00613 & 10.5 \\
\hline 500 & 1.334 & 0.03671 & 38.8 \\
\hline
\end{tabular}

Table 8: Indicates the data obtained from the plot of In(qe-qt) versus $t$.

of one type of binding site (homogeneous surface). However, if the plot deviates from linearity, then the adsorbent consists of more than one type of binding site. The regression value obtained is 0.903 which show high adsorption of chlorothalonil. Based on the higher regression values in Quasi-Langmuir isotherms (Scatchard plot), the experiment was found to follow this model. Since the data obtained in this study has the highest regression in this model, it's evident that the adsorbent consist of only one type of binding site (homogeneous surface) [26].

\section{Adsorption kinetics}

Kinetics is the major approaches used to evaluate biosorption dynamics whereby the constants are used to optimize the biosorption time. To examine the controlling mechanism of the biosorption process, various kinetic models were used to test the experimental data. In order to obtain the rate constants and order of sorption reaction, pseudo-first-order and pseudo-second-order kinetics model were applied to the kinetic data obtained at $298 \mathrm{~K}$ at an optimize $\mathrm{pH}$ of 7 and initial pesticide residue concentration of $100,200,300,400,500 \mathrm{mg} / \mathrm{L}$ and at 15, 30, 45, 60 minutes shaking time.

\section{Pseudo-first-order model}

Different kinetic models have been used to describe the experimental data of heavy metals adsorption on biomass $[13,14]$. Pseudo first order Kinetic model of Lagergren [13] is based on the solid capacity for sorption analysis and expressed as follows,

$$
\mathrm{dqt} / \mathrm{dt}=\mathrm{kf}(\mathrm{qe}-\mathrm{qt})
$$

where qt is the amount of adsorbate adsorbed at time $t(\mathrm{mg} / \mathrm{g})$, $\mathrm{kf}$ is the rate constant of pseudo-first-order kinetics ( $\min )$ and $t$ is the time ( $\mathrm{min}$ ). The integration of Eq. (3) with the initial condition, $\mathrm{qt}=0$ at $\mathrm{t}=0$ leads to the pseudo first-order rate equation:

\section{$\ln (\mathrm{qe}-\mathrm{qt})=\ln \mathrm{qe}-\mathrm{kft}$}

A straight line of $\ln$ (qe-qt) versus $t$ suggests the applicability of this kinetic model. Pseudo first order rate constant $(k f)(1 / \mathrm{min})$ can be determined from the slope of the plot. This equation is, however, valid only for the initial adsorption period. The following figure and table shows the data obtained from the plot of experimental data.

\section{Pseudo-second-order model}

The pseudo-second order reaction kinetic model based on the sorption equilibrium capacity can be expressed as [15],

$$
\mathrm{dqt} / \mathrm{dt}=\mathrm{ks}(\mathrm{qe}-\mathrm{qt})
$$

where $k \mathrm{~S}$ is the pseudo-second-order rate constant $(\mathrm{g} / \mathrm{mg} \mathrm{min})$. Integrating Eq. (4) and noting that $q \mathrm{t}=0$ at $t=0$, the following equation is obtained:

\section{$\mathrm{t} / \mathrm{qt}=1 / \mathrm{ksqe}+1 / \mathrm{qet}$}

The plot $t / q t$ versus $t$ should give a straight line if second-order kinetics are applicable, and $q e$ and $k s$ can be determined from the slope and intercept of the plot, respectively. The initial sorption rate, $h$ ( $\mathrm{mg} / \mathrm{g} \mathrm{min}$ ), as $t \rightarrow 0$ can be defined as

\section{$\mathrm{h}=\mathrm{ksqe}^{2}$}

The straight line plot for the pseudo first order sorption kinetic model between $\ln (\mathrm{qe}-\mathrm{qt}$ ) vs. $t$ was plotted (Figure 9) for sorption of chlorothalonil. The value of the rate constant calculated from the slope of plot with the correlation coefficient ranged from 0.00028 to 0.07347 . The linear plot of pseudo second order kinetic model was also plotted between $t / q$ t. vs. $t$, and sorption capacity and pseudo second order rate constants qe and ks were calculated from the slope and intercept of the plot (Figure 10). The pseudo second order kinetic constant ks and sorption capacity qe were $0.3236 \mathrm{~g} /$ $\mathrm{mg} \min$ to $10.6346 \mathrm{mg} / \mathrm{g}$. A high coefficient of determination, i.e., 0.998, was obtained for the pseudo second order kinetic model, and these results were good in comparison to pseudo first order model, indicating that process of uptake of chlorothalonil followed pseudo second order rate expression (Table 9). In addition to this initial sorption rate $(\mathrm{h})$ were also calculated by using Eq. 21 . The initial sorption rate were $0.0136,0.079,0.6329,3.021$ and $4.807 \mathrm{mg} / \mathrm{min}$ for $100,200,300,400$ and $500 \mathrm{mg} / \mathrm{ml}$ respectively (Table 10 ).

\section{Intraparticle diffusion model}

The possibility of intra-particle diffusion was explored by using the intra-particle diffusion model,

$$
\mathrm{q}_{\mathrm{t}}=\mathrm{k}_{\mathrm{id}} \mathrm{t}^{1 / 2}+\mathrm{I}
$$

where $k \mathrm{id}$ is the intra-particle diffusion rate constant. According

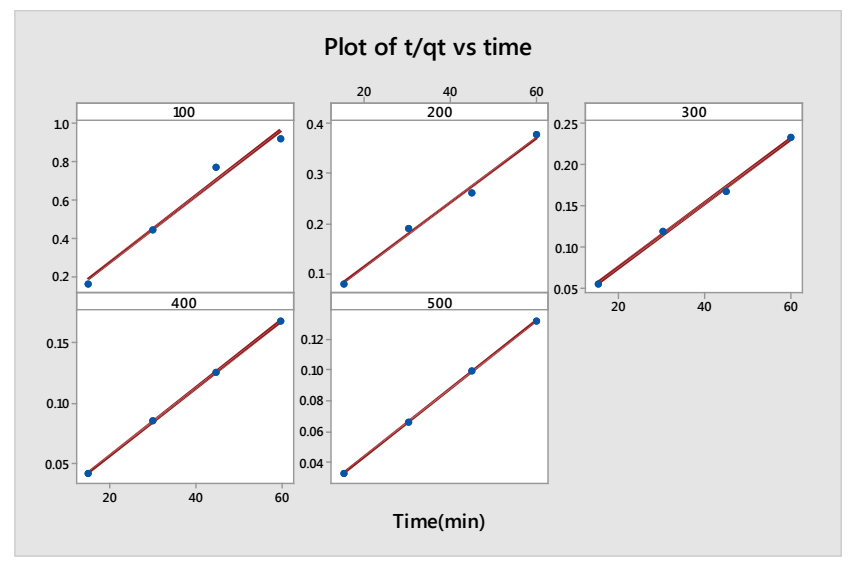

Figure 9: Pseudo second order model plot

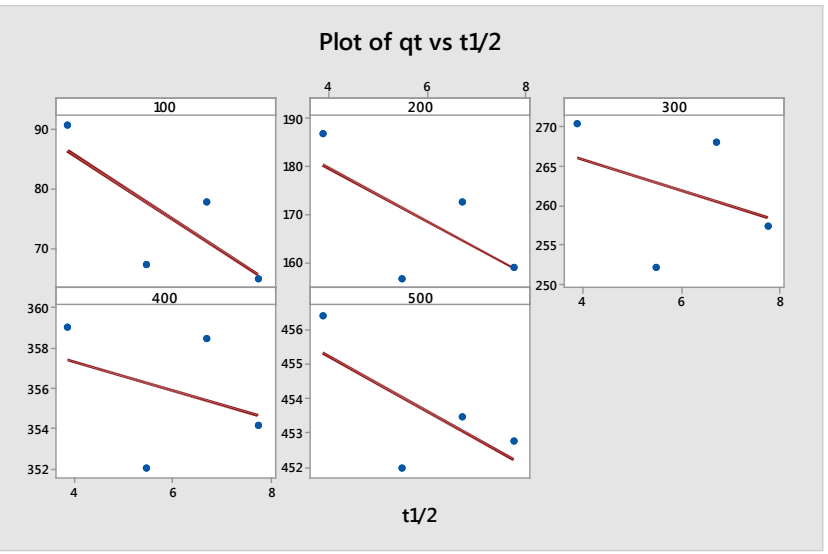

Figure 10: Intra-particle diffusion model the data obtained from the plots in Figure 10 above are given in Table 10 . 


\begin{tabular}{|c|c|c|c|c|c|}
\hline Initial Conc & $\mathbf{1} / \mathbf{k}_{\mathbf{s}} \mathbf{q}_{\mathbf{e}}{ }^{\mathbf{2}}$ & $\mathbf{1 / \mathbf { q } _ { \mathbf { e } }}$ & $\mathbf{k}_{\mathbf{s}}$ & $\mathbf{H}$ & $\mathbf{R}^{\mathbf{2}}$ \\
\hline 100 & 0.07347 & 0.01734 & 0.23602 & 13.6109 & 98.0 \\
\hline 200 & 0.01254 & 0.006399 & 0.51029 & 79.7448 & 99.1 \\
\hline 300 & 0.001580 & 0.003877 & 2.45379 & 632.9113 & 99.7 \\
\hline 400 & 0.000331 & 0.002822 & 8.52568 & 3021.1480 & 100 \\
\hline 500 & 0.000208 & 0.002212 & 10.6346 & 4807.6923 & 100 \\
\hline
\end{tabular}

Table 9: Pseudo second order kinetic parameter.

\begin{tabular}{|c|c|c|c|}
\hline Initial Conc & $\mathbf{I}$ & $\mathbf{k}_{\text {id }}$ & $\mathbf{R}^{\mathbf{2}}$ \\
\hline 100 & 107.3 & 5.382 & 58.3 \\
\hline 200 & 201.6 & 5.522 & 43.9 \\
\hline 300 & 273.7 & 1.958 & 14.2 \\
\hline 400 & 360.2 & 0.719 & 12.2 \\
\hline 500 & 458.5 & 0.806 & 47.6 \\
\hline
\end{tabular}

Table 10: Intra-particle diffusion model parameters.

to equation 22 , a plot of $q \mathrm{t} 1 / 2$ versus $t$ should be a straight line with a slope $\mathrm{k}_{\mathrm{id}}$ and intercept $\mathrm{I}$ when adsorption mechanism follows the intra-particle diffusion process as shown in Figure 10. Low regression values were obtained with the plots not passing the origin. The values for $\mathrm{k}_{\mathrm{id}}$ and I were in a range of 5.382 to 0.806 and 107 to 458.5 respectively. The value of I gives an insight about the thickness of the boundary layer. The larger the intercept, the greater is the boundary layer effect [27]. Deviation from the lines from the origin may have resulted from difference in the rate of mass transfer in the initial and final stages of adsorption. This is an indication that pore diffusion is not the sole rate controlling step.

\section{Thermodynamic study}

Thermodynamic properties of a adsorption/desorption process are necessary to conclude whether the process is spontaneous or nonspontaneous. The Gibbs free energy change, $\Delta G$, is an indication of spontaneity of a chemical reaction and therefore is an important criterion for spontaneity. Also, both energy and entropy factors must be considered in order to determine the Gibbs free energy of the process. Reactions occur spontaneously at a given temperature if $\Delta G$ is a negative quantity. The free energy of a biosorption reaction, considering the biosorption equilibrium constant $K c$ is given by the following equation,

\section{$\Delta G=-\mathrm{RT} \ln \mathrm{Kc}$ or $\mathrm{K}_{\mathrm{F}}$}

where $\Delta G$ is the standard free energy change $(\mathrm{kJ} / \mathrm{mol}), \mathrm{R}$ the universal gas constant, $8.314 \mathrm{~J} / \mathrm{mol} \mathrm{K}$, and $T$ is absolute temperature (K). Kc is the equilibrium constant, which is calculated from following equation,

$$
\mathrm{Kc}=\mathrm{C}_{\mathrm{Ae}} / \mathrm{C}_{\mathrm{e}}
$$

where $C_{\mathrm{Ae}}$ is the equilibrium concentration of metal ion on the sorbent $(\mathrm{mg} / \mathrm{L})$ and $\mathrm{C}_{\mathrm{e}}$ is the equilibrium concentration of metal ion in bulk solution $(\mathrm{mg} / \mathrm{L})$.

\section{Conclusion}

In this study, investigation of equilibrium sorption was carried at $298 \mathrm{~K}$. the sorption data of chlorothalonil adsorption onto Nairobi river sediment was fitted to Freundlich, Langmuir, Quasi Langmuir 1, Temkin, Dubinin-Radushkevich and Scatchard isotherm models out of which the data fitted the quasi Langmuir (Scatchard plot) best with highest regression values of 99.8-100. From the kinetics study, the adsorption of chlorothalonil obeyed pseudo second order kinetics. It's therefore in conclusion that different models should be used to fit adsorption experimental data to evaluate the best model to explain adsorption of different pesticide molecule.

\section{Acknowledgements}

The authors wish to express their sincere gratitude to VicRes and the InterUniversity Council of East Africa for funding this research work. Moreover, the writers wish to acknowledge the Kenya Bureau of Standards (KEBS) for donating the Chlorothalonil pesticide and for availing HPLC instrument facilities.

\section{References}

1. Limousin G, Gaudet JP, Charlet L, Szenknect S (2007) Sorption isotherms: a review on physical bases, modeling, and measurement. Appl Geochem 22: 249-275.

2. Allen SJ, Mckay G, Porter JF (2004) Adsorption isotherm models for basic dye adsorption by peat in single and binary component systems. J Colloid Interface Sci 280: 322-333.

3. Kumar KV, Sivanesan S (2007) Sorption isotherm for safranin onto rice husk: comparison of linear and non-linear methods. Dyes Pigments 72: 130-133.

4. Ghiaci M, Abbaspur A, Kia R, Seyedeyn F (2004) Equilibrium isotherm studies for the sorption of benzene, toluene, and phenol onto organo-zeolites and assynthesized MCM-41. Sep Purif Technol 40: 217-229.

5. Ncibi MC (2008) Applicability of some statistical tools to predict optimum adsorption isotherm after linear and non-linear regression analysis. J Hazard Mater 153: 207-212.

6. Bulut E, Ozacar M, Sengil IA (2008) Adsorption of malachite green onto bentonite: equilibrium and kinetic studies and process design. Micropor Mesopor Mater 115: 234-246.

7. Malek A, Farooq S (1996) Comparison of isotherm models for hydrocarbon adsorption on activated carbon. AIChE J 42: 3191-3201.

8. Langmuir I (1916) The constitution and fundamental properties of solids and liquids. J Am Chem Soc 38: 2221-2295

9. Myers AL, Prausnitz JM (1965) Thermodynamics of mixed gas adsorption AIChE J 11: 21-129.

10. Dubinin MM (1960) The potential theory of adsorption of gases and vapors for adsorbents with energetically non-uniform surface. Chem Rev 60: 235-266.

11. Ruthven DM (1984) Principles of Adsorption and Adsorption Processes. Wiley pp:464.

12. Igwe JC, Abia AA (2006) A bio separation process for removing heavy metals from waste water using bio sorbents. African Journal of Biotechnology 5: 1167-1179.

13. Lagergren $S$ (1898) On the theory of the so-called adsorption of solute substances. The Royal Swedish Vetenkapsakademiens Documents 24: 1-39.

14. Ho YS, Ofomaja AE (2006) Biosorption thermodynamics of cadmium on coconut copra meal as biosorbent. Biochem Eng J 30: 117-123.

15. Ho YS (2006) Review of second order models for adsorption systems. J Hazard Mater 136: 681-689.

16. Kannan K, Sundaram MM (2001) Kinetics and mechanism of removal of methylene blue by adsorption on various carbons. A comparative study Dyes Pigments 51: 25-40.

17. Mall ID, Srivastava VC, Kumar GVA, Mishra IM (2006)Characterization and utilization of mesoporous fertilizer plant waste carbon for adsorptive removal of dyes from aqueous solution. Colloid Surf A 278: 175-187.

18. Vanderborght M, Van Grieken E (1997) Enrichment of trace metals in water by adsorption on activated carbon. Analytical Chemistry 49: 311-316.

19. De Boer JH (1968) The Dynamical Character of Adsorption. 2(eds) Oxford University Press London.

20. Vermeulan TH, Vermeulan KR, Hall LC (1966) Pore- and Solid-Diffusion Kinetics in Fixed-Bed Adsorption under Constant-Pattern Conditions. Fundamental Ind Eng Chem 5: 212-223.

21. Webber TW, Chakkravorti RK (1974) Pore and solid diffusion models for fixedbed adsorbers. AIChE J 20: 787-794

22. Freundlich $\operatorname{HMF}(1906)$ On the adsorption in solutions. Journal of Physica Chemistry (Leipzig) 57: 385-470. 
Citation: Kamau J, Kamau G (2017) Modeling of Experimental Adsorption Isotherm Data for Chlorothalonil by Nairobi River Sediment. Mod Chem Appl 5: 203. doi: 10.4172/2329-6798.1000203

23. Yadav S, Tyagi DK, Yadav OP (2011) Equilibrium and kinetics studies on adsorption of aniline blue from aqueous solution onto rice Husk carbon. International Journal of Chemistry Research 25: 59-64.

24. Temkin MI, Pyzhev V(1940) Kinetics of ammonia synthesis on promoted iron catalysts. Acta Physicochim URSS 12: 217-222.

25. Dubinin MM, Radushkevich LV (1947) Equation of the characteristic curve of activated charcoal Proceedings of the Academy of Sciences. Chemistry Section 55: 331-333.
26. James K, Immaculate N, Stanley M (2012) Adsorption of 2, 4, 5, 6 Tetra chloro iso phthalonitriles (Chlorothalonil) By Nairobi River Sediments Adsorption Characteristics and Related Thermodynamic Data. International Journal of Bio chemi physics 20: 1-14.

27. Anirudhan TS, Suchithra PS (2012) equilibrium, kinetic and thermodynamic modelling for the adsorption of heavy metals onto chemically modified hydrotactile. Ind J Chem Technol 17: 247-259. 